\title{
BMJ Open Quality Reducing congestion in the emergency driveway of a small hospital in New Delhi, India
}

To cite: Bhartia S, Wahi P, Sharma A. Reducing congestion in the emergency driveway of a small hospital in New Delhi, India. BMJ Open Quality 2021;10:e001398. doi:10.1136/ bmjoq-2021-001398

- Additional supplemental material is published online only. To view, please visit the journal online (http://dx.doi.org/10. 1136/bmjoq-2021-001398).

Received 10 February 2021 Accepted 15 May 2021

\section{Check for updates}

(C) Author(s) (or their employer(s)) 2021. Re-use permitted under CC BY-NC. No commercial re-use. See rights and permissions. Published by BMJ.

Quality, Sitaram Bhartia Institute of Science and Research, New Delhi, Delhi, India

Correspondence to

Saru Bhartia;

saru.bhartia@sitarambhartia.org

Saru Bhartia, Pradaya Wahi, Ashok Sharma

\section{BACKGROUND}

Hospital parking contributes to poor patient care $^{1}$ and is a common patient problem ${ }^{23}$ in many facilities including ours. Sitaram Bhartia Institute of Science and Research (SBISR) in New Delhi, India was built as a research facility that later started offering outpatient and inpatient medical services. As the building was not designed to be a hospital, there is only a narrow driveway allowing single lane traffic to and from the emergency drop off area (figure 1). Since this driveway is used by all the vehicles entering the hospital, this leads to the congestion and hinders ambulance movement. We have used quality improvement (QI) methodology to deliver better clinical care since 2010 and we decided to try this methodology to reduce congestion in the emergency driveway.

\section{METHODS OF IMPROVEMENT}

Before the initiation of the project, all vehicles approaching hospital gate were entering through the emergency driveway. We took up the improvement initiative with an aim to reduce the number of vehicles entering the emergency driveway. We formed a team consisting of a security manager, security guard, billing clerk, quality officer and quality consultant. Security guards had data about three categories of vehicles entering the emergency driveway. The first category was of vehicles that picked up inpatients, typically from the emergency drop-off area, who had been discharged (median of 200 vehicles per month). The second category was of vehicles that dropped off outpatients (median of 900 vehicles per month). The third category of vehicles entered for other reasons such as collection of biomedical waste, laundry, and so on. The number of vehicles in the third category was small so the team decided to focus on the first two.

We measured the number of vehicles approaching the hospital gate to request entry into the emergency driveway (inpatient and outpatient) and the number of vehicles that actually entered the emergency driveway (inpatient and outpatient).

We decided to start by reducing the number of vehicles entering to pick up discharged inpatients. We started with this because we thought it would be easier to fix and would give us some quick results. The security guards explained to the QI team that vehicles coming to pick discharged inpatients would block the driveway for about $6-10 \mathrm{~min}$ while the driver was accompanying the patient from the hospital floor. The team identified a spot inside the premises before the emergency driveway entrance so that the vehicles could be parked without creating blockage. We decided to test whether it was feasible to reserve that space for people picking up inpatients. We tested this using a plan-do-study-act (PDSA) cycle for 2 days in May 2017. From this PDSA, we learnt that people were able to park at the identified spot without causing any congestion. Most drivers were happy with the dedicated parking spot but some drivers refused to park there and continued to block the driveway. We ran a second PDSA cycle in June to test how many drivers would park in the designated spot on request by the security guards. Guards directing drivers to the parking spot resulted in 118 fewer inpatient vehicles entering the emergency driveway, representing $69 \%$ reduction of inpatient vehicles. Because some people were ignoring the security guards' requests we decided to involve staff from the billing desk. When people settled their hospital bill, the clerks would tell them that they should park their car at the designated spot. We thought that this change would reduce resistance to the guards' requests. We also thought it would improve sustainability as there was high turnover of security guards while the billing clerks were much more stable. We ran our third PDSA cycle in September 2017 to test 


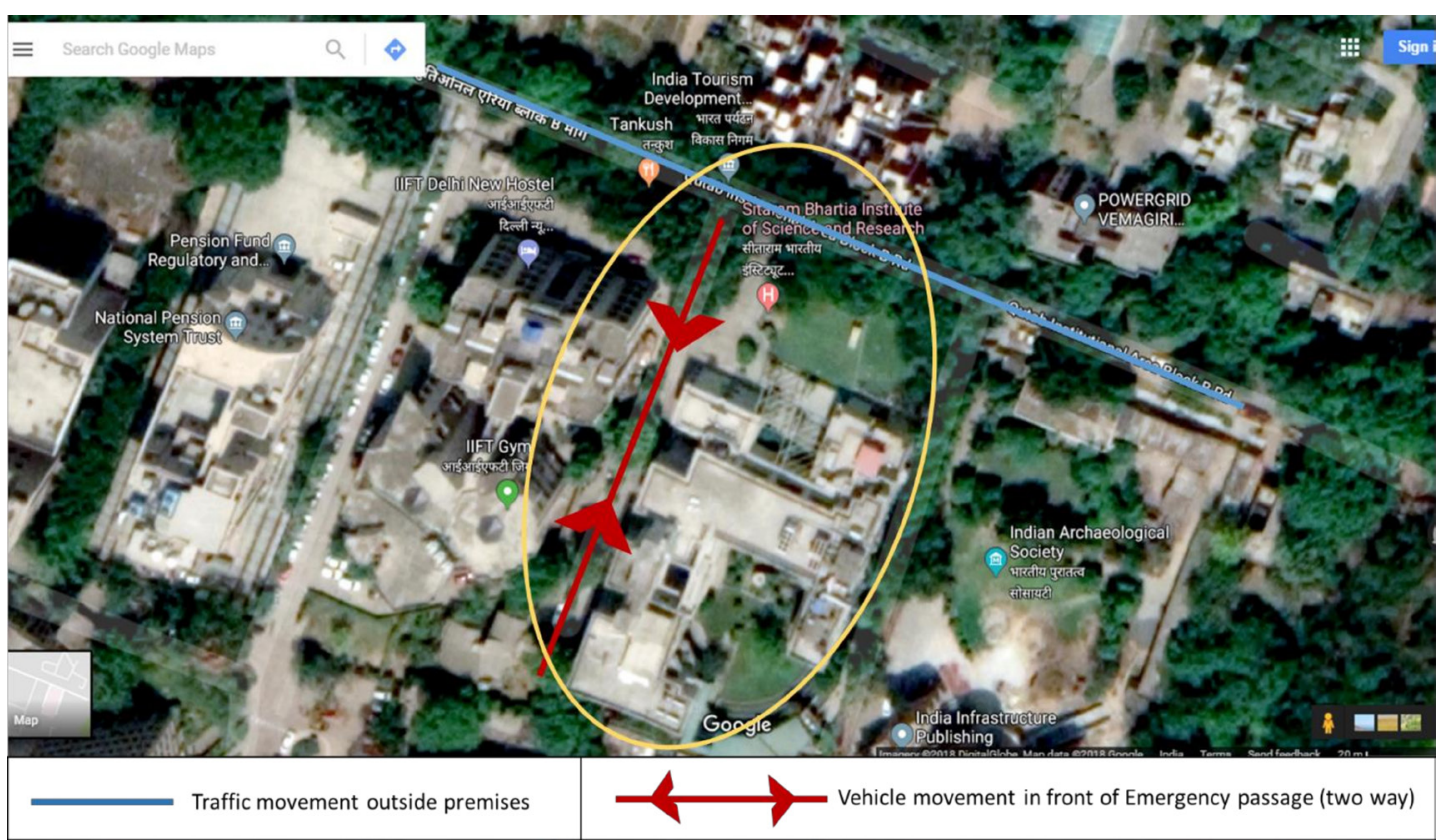

Figure 1 Vehicle movement in front of the emergency passage.

if involving the billing clerks was effective. During this month, 175 fewer inpatient vehicles entered the emergency driveway representing a reduction of $75 \%$ inpatient vehicles.

After reducing the number of vehicles for inpatients, we focused on reducing the number of vehicles entering to drop off outpatients. We first tested the idea of security guards requesting drivers to drop patients outside the premises. Patients who were unable to walk or required emergency care were exempted. We ran our fourth PDSA cycle to test this idea in October 2017. We found that 413 outpatient vehicles entered the driveway, representing a $54 \%$ reduction of outpatient vehicles entering the emergency passage. We learnt that some patients did not listen to the guards because they thought the guards were just being difficult. To address this, the guards came up with the idea of placing a signboard stating that entry of vehicles is restricted by hospital policy. We tested the effectiveness of the signboard though our fifth PDSA in March 2018 and found that 1059 fewer vehicles entered, representing a reduction of $82 \%$ of outpatient vehicles.

\section{RESULTS}

After implementing all the changes for the inpatient and outpatient vehicles, there has been a significant reduction of the vehicles entering the emergency passage.

We used the run chart to analyse our quantitative data. We used the first 4 months to calculate the baseline median. We used the run chart rules proposed by Anhøj and Olesen ${ }^{4}$ and defined the shift as a run of eight or more points on one side of the median. When we identified a shift, we used the eight data points that constituted the shift to calculate the new median.

The number of vehicles (inpatient and outpatient) entering the emergency driveway has reduced from a median of 1392 per month to a median of 106 per month (online supplemental annexure I-graph).

\section{CONCLUSION}

We succeeded in reducing the number of vehicles entering the hospital premises from a median of 1392 per month to 691 and further to median of 106 per month. As with all QI projects, involvement of frontline staff with practical knowledge of the problem was critical. The security guard on the QI team came up with solutions such as placing a signboard to reduce drivers' objections. The guard also worked with other security guards to help implement changes.

To our knowledge, this is the first report of a hospital using QI methodology to reduce parking congestion. We believe that other hospitals, particularly in developing countries where facilities have design limitation, could use a similar approach to ease their parking problems and improve patient experience.

Twitter Saru Bhartia @Saru4q

Acknowledgements We acknowledge the support and encouragement of Abhishek Bhartia, director, and Dr Sneh Bhargava, medical director. We would particularly like to highlight the contribution of our security supervisor Hitler, who engaged the security staff in the improvement effort.

Contributors All authors contributed to this QI report. All authors planned and executed the project. PW and AS collected the data. SB drafted the report with PW. All authors reviewed the final copy of the report.

Funding Publication of this article is made Open Access with funding from the Nationwide Quality of Care Network.

Map disclaimer The depiction of boundaries on the map(s) in this article does not imply the expression of any opinion whatsoever on the part of BMJ (or any member of its group) concerning the legal status of any country, territory, jurisdiction or area or of its authorities. The map(s) are provided without any warranty of any kind, either express or implied.

Competing interests None declared. 
Patient consent for publication Not required.

Provenance and peer review Not commissioned; externally peer reviewed.

Supplemental material This content has been supplied by the author(s). It has not been vetted by BMJ Publishing Group Limited (BMJ) and may not have been peer-reviewed. Any opinions or recommendations discussed are solely those of the author(s) and are not endorsed by BMJ. BMJ disclaims all liability and responsibility arising from any reliance placed on the content. Where the content includes any translated material, BMJ does not warrant the accuracy and reliability of the translations (including but not limited to local regulations, clinical guidelines, terminology, drug names and drug dosages), and is not responsible for any error and/or omissions arising from translation and adaptation or otherwise.

Open access This is an open access article distributed in accordance with the Creative Commons Attribution Non Commercial (CC BY-NC 4.0) license, which permits others to distribute, remix, adapt, build upon this work non-commercially, and license their derivative works on different terms, provided the original work is properly cited, appropriate credit is given, any changes made indicated, and the use is non-commercial. See: http://creativecommons.org/licenses/by-nc/4.0/.

\section{REFERENCES}

1 Gilbert D. Car parking is a clinical quality issue. BMJ 2015;350:h1312-12.

2 Pather S, Tai D, Philp S, et al. A prospective study assessing patient satisfaction at a large tertiary gynecologic oncology/dysplasia unit. Patient Relat Outcome Meas 2010;1:149-52.

3 Lagu T, Goff SL, Craft B, et al. Can social media be used as a hospital quality improvement tool? J Hosp Med 2016;11:52-5.

4 Anhøj J, Olesen AV. Run charts revisited: a simulation study of run chart rules for detection of non-random variation in health care processes. PLoS One 2014;9:e113825. 